\title{
La función de la iconografía en las culturas calcolíticas del Levante meridional: una lectura a partir del concepto de esferas de interacción
}

(1) Pablo F. Jaruf

Universidad de Buenos Aires

Fecha de recepción: 15 de mayo de 2018. Fecha de aceptación: 9 de junio de 2018.

\section{Resumen}

El Calcolítico del Levante meridional se extiende desde el 4500 al 3800/3600 a.C., período que corresponde a las culturas arqueológicas Ghassuliense y Golanita. Una de las características principales de estas dos culturas son sus expresiones iconográficas que, además de su cantidad, decoran vasijas y otros objetos de distintos materiales y tipología. El objetivo central de este artículo es proponer que parte de estos motivos iconográficos pudieron haber sido símbolos que formaban parte de un código común que favorecía las interacciones entre las distintas regiones del Levante meridional. Asimismo, se plantea que hacia fines de este período dicho código pudo haber sido apropiado de manera paulatina por un sector cada vez más restringido de la sociedad, posiblemente los líderes aldeanos. Para explorar esta posibilidad se ha analizado el repertorio iconográfico a partir del concepto de esferas de interacción.

\begin{abstract}
The Chalcolithic of the southern Levant extends from 4500 to 3800/3600 BC, corresponding to the Ghassulian and Golanian archaeological cultures. One of the main features of these two cultures is their iconographic expressions which, besides their quantity, decorate vessels and other objects of different materials and typology. The main goal of this article is to propose that part of these iconographic motifs could have been symbols that were part of a common code that favored interactions between the different regions of the southern Levant. Likewise, it is suggested that by the end of this period such a code could have been gradually appropriated by an increasingly restricted sector of society, possibly the village leaders. To explore this possibility, the iconographic repertoire has been analyzed following the approach of interaction spheres.
\end{abstract}

Palabras clave

Calcolítico Levante meridional esferas de interacción iconografía símbolos

Keywords

Chalcolithic Southern Levant Interaction Spheres Iconography Symbols 
1. En este artículo empleamos el término Calcolítico para referirnos exclusivamente al período que abarcan las culturas Ghassuliense y Golanita (cf. Gilead, 2011: 13-14, 20-21; Milevski, 2013: 195).

\section{Introducción}

El Calcolítico del Levante meridional se extiende, aproximadamente, desde el 4500 hasta el 3800/3600 a.C. ${ }^{1}$. Según el registro material, este período corresponde a las culturas Ghassuliense y Golanita. Mientras que la segunda se restringe a los Altos del Golán (Epstein, 1998), la primera abarca las regiones de la Alta Galilea, la costa mediterránea, el piedemonte contiguo, las tierras altas centrales, el valle del Jordán, el desierto de Judea y el norte del Néguev (Gilead, 2011: 13-14) (Fig. 1). Contamos también con una tercera cultura arqueológica, la Timnita, que se ubica en el centro y sur del Néguev, y que se proyecta al noreste de la península de Sinaí, pero que presenta amplias diferencias con las anteriores, como atestigua la ausencia tanto de cerámica como de metalurgia (Rosen, 2017: 131-166).

Entre los rasgos que caracterizan a las culturas Ghassuliense y Golanita destacan las viviendas de arquitectura rectangular con cimientos de piedra y paredes de ladrillos, los cuencos de cerámica y de basalto "en forma de V" ( $v$-shaped bowls), y el aumento de expresiones iconográficas (cf. Rowan y Golden, 2009; Garfinkel, 2014; Levy, 2014; Rowan, 2014). Los especialistas, de hecho, concuerdan que una de las características principales de este período es la "explosión de expresiones visuales" (Rowan y Golden, 2009: 56), por lo que es "excepcional en sus manifestaciones artísticas" (Garfinkel, 2014: 1450). Este repertorio iconográfico consiste en estatuillas de terracota, de cerámica, de piedra, de hueso y de marfil, en pinturas murales, y en decoraciones antropomorfas y zoomorfas sobre cuencos, pilares, herramientas y otros objetos (cf. Elliott, 1977; Epstein, 1978; Perrot y Ladiray, 1980; Cameron, 1981; Epstein, 1982; Tadmor, 1986; Beck, 1989; Merhav, 1993; Commenge et al., 2006; Milevski, 2010; Ilan y Rowan, 2012; Milevski y Gandulla, 2014; Shalem, 2014; Drabsch, 2015; Shalem, 2015).

A nuestro entender, este aumento de las expresiones iconográficas y la reproducción de un conjunto reducido de motivos serían consecuencia de la existencia de un código simbólico común, merced al cual las distintas regiones del Levante meridional habrían logrado incrementar y fortalecer sus interacciones durante el Calcolítico. Para demostrar esta hipótesis, primero, verificamos el aumento de las vinculaciones interregionales en el contexto socioeconómico del período y, segundo, procedimos a analizar el conjunto de la evidencia iconográfica a partir del concepto de esferas de interacción, prestando atención tanto a las variables regionales y cronológicas, como así también a la tipología de los objetos y el material que se escogió para representar estas imágenes.

\section{El concepto de esferas de interacción}

El concepto de esferas de interacción fue formulado hace más de cinco décadas por J. R. Caldwell (1964). Dicho concepto tenía por objeto explicar la recurrencia de determinados artefactos en contextos mortuorios pertenecientes a la llamada "situación Hopewell" del sudeste norteamericano, entre el 100 a.C. y el 500 d.C. Para Caldwell, estos objetos eran indicadores de interacciones 
sociales, fundamentalmente religiosas, entre culturas regionales autónomas. Desde su punto de vista, la regularidad y densidad de estas interacciones habían promovido la adopción de ideas e innovaciones entre distintas poblaciones.

Este concepto fue luego aplicado al estudio de la Prehistoria Tardía del Próximo Oriente, en especial al período Neolítico Pre-Cerámico B (PPNB) (ca. 8500-7000 a.C.) (Bar-Yosef y Belfer-Cohen, 1989), y a la secuencia de culturas cerámicas mesopotámicas: Hassuna, Samarra, Halaf, 'Ubaid y Uruk (ca. 63003000 a.C.) (Yoffee, 1993). En el caso del PPNB, O. Bar-Yosef y A. Belfer-Cohen ${ }^{2}$ (1989) sostuvieron que las semejanzas en la evidencia material de los sitios del Levante y Anatolia centro-oriental, en especial la relativa a la industria lítica, la arquitectura, las prácticas de subsistencia y las expresiones simbólicas, eran el resultado de una red de contactos supra-regionales destinada a la circulación de determinadas materias primas y productos terminados.

En relación a esto último, E. Asouti (2006) ha propuesto analizar de manera diferente el problema de la "esfera de interacción del PPNB". Por un lado, aborda las prácticas de intercambio desde un enfoque contextual, es decir, como prácticas sujetas no sólo a criterios utilitarios sino también a los significados simbólicos que se les atribuían a los objetos intercambiados. Por otro lado, enfatiza las variables locales, a las que interpreta como resultado de negociaciones entre identidades que operaban a distintos niveles: individual, familiar, de género, de fracción y/o comunitaria (Asouti, 2006: 111-113). Según esta autora, las tensiones al interior de, y entre, comunidades, resultado de los cambios en las prácticas económicas y sociales, se resolvieron por medio de la creación de identidades que lograron cohesionar a los diferentes miembros de una o varias comunidades (Asouti, 2006: 118-120).

Para el caso de la secuencia de culturas cerámicas mesopotámicas, N. Yoffee (1993) distinguió dos tipos de esferas de interacción. Por un lado, las de escala regional, cuya interacción se daba entre comunidades que compartían una misma región en términos ambientales: las culturas de Hassuna y de Samarra (Yoffee, 1993: 263-265). Por otro lado, las de escala interregional, a las cuales subdividió en esferas de interacción económica y esferas de interacción cultural (Yoffee, 1993: 265-267). La primera, dentro de la cual incluye a la cultura Halaf, consistía en una red de intercambio en la que las élites locales controlaban la circulación de bienes a través de amplias distancias geográficas y sociales. La segunda, correspondiente a la cultura 'Ubaid, estaba caracterizada en cambio por los rasgos culturales, en particular por la planta de los edificios.

G. Stein (2010), en una reevaluación de la esfera de interacción 'Ubaid, no sólo enfatiza las variables regionales, en desmedro de las semejanzas, sino que también destaca la cuestión relativa a la construcción y negociación de las identidades locales. En sus propias palabras:

(...) los vínculos cruciales de la esfera de interacción de 'Ubaid eran aquellos relacionados a la noción amplia de identidad, tanto a nivel personal como comunal, por la que los individuos y los grupos se definían a sí mismos como parte de una oikouménē inclusiva mayor (Stein, 2010: 38; nuestra traducción).
2. Es necesario aclarar que si bien Bar-Yosef y Belfer-Cohen aplican este concepto, no hacen referencia explícita al modelo de Caldwell. 
De esta manera, en concordancia con lo planteado por Asouti, este autor considera que la coexistencia de semejanzas y diferencias en la cultura material entre distintas regiones es resultado de la expresión de identidades que actúan tanto a nivel local como supralocal.

Un enfoque parecido es el que propuso B. Gandulla (2005) en su estudio sobre las interacciones producidas en el territorio de la llamada Media Luna Fértil Periférica (MLFP), esto es, el Transcáucaso, Anatolia Centro-Oriental y SiriaPalestina, durante la Edad del Bronce Antiguo II-III (ca.3000-2400 a.C.). Según su análisis, las semejanzas en la cerámica y la arquitectura, e incluso en el ordenamiento de las casas a nivel de las aldeas, serían indicios de la existencia de "un conjunto de valores, símbolos e instituciones culturales comunes [semejantes a aquellas] que Yoffee ejemplifica en la formación de un sistema de creencias en el período 'Ubaid” (Gandulla, 2005: 37).

De manera reciente, I. Milevski y otros investigadores (2016) han planteado la posible existencia de una esfera de interacción cultural en prácticamente la misma macro-región que la MLFP, la cual se habría desarrollado de manera previa en las fases neolíticas tardías. A su entender, estas regiones habrían compartido motivos femeninos, de árboles y de animales enastados, lo que las vincularía entonces con la esfera de interacción Halaf, en particular con las regiones del Éufrates medio y de la Alta Mesopotamia.

El objetivo del presente artículo, a diferencia de los trabajos mencionados, no es proceder a analizar las interrelaciones en espacios geográficos tan amplios, sino simplemente concentrarnos en el Levante meridional, donde sin embargo existe una suficiente variedad de condiciones ambientales que permite distinguir entre distintas regiones (Levy, 1995: 229; Lovell, 2001: 51; Rowan y Golden, 2009: 14-20). Desde nuestro punto de vista, las interacciones entre estas últimas, a pesar de su menor extensión, también pueden ser mejor comprendidas a partir del uso del concepto de esferas de interacción.

Los resultados de investigación referidos en los párrafos anteriores nos resultan de sumo interés, pues nos permiten plantear que las formas de intercambio no sólo habrían estado condicionadas por los significados simbólicos que se le atribuía a los bienes, por lo que pudieron haber desempeñado un rol relevante en la conformación de las identidades, sino también que en las susodichas interacciones siempre habrían participado, en diferente grado, elementos tanto locales como foráneos.

Otro aspecto a considerar es el impulso que habrían implicado estas interacciones para el proceso de jerarquización social durante la Prehistoria Tardía. Si bien en un comienzo pudieron ser promovidas por distintas agrupaciones, con el tiempo los líderes aldeanos habrían intentado controlarlas en su provecho, acentuando sus diferencias con el resto de los integrantes de sus respectivas comunidades, a la vez que se identificaban en mayor grado con los líderes de otras aldeas. Como plantea Yoffee para el caso de la cultura Halaf: 
tales interacciones, y nuevas formas de riqueza y de estatus se crearon a través de la manipulación de tales símbolos y de los intentos para controlar el flujo de bienes hacia las elites (Yoffee, 1993: 268; nuestra traducción).

A nuestro entender, estas mismas consideraciones pueden ser aplicadas al estudio de la iconografía del período Calcolítico pues, para que las vinculaciones entre las distintas regiones del Levante meridional se materializaran, habría sido necesario que paralelamente se desarrollara un código simbólico común que le sirviera de sustento. Nuestra hipótesis es que el contenido principal de este código, es decir, los símbolos que lo componían, habría estado conformado por un conjunto reducido de motivos iconográficos.

\section{Contexto socioeconómico y aumento de las interacciones interregionales}

El origen de las culturas Ghassuliense y Golanita, como dijimos con anterioridad, se puede situar en torno al 4500 a.C. A partir de entonces se verifica un incremento en la cantidad de sitios, muchos de ellos ubicados en regiones antes poco pobladas, como el sur del valle del Jordán y el norte del Néguev, así como también un aumento de sus tamaños, lo que es indicio de una mayor densidad poblacional (Bourke, 2008: 114-118; Winter-Livneh et al., 2010: 285). Este crecimiento demográfico habría implicado una mayor producción agrícola, como se infiere a partir del aumento en el tamaño, cantidad y variedad de silos y de vasijas de almacenamiento (Garfinkel, 1999: 303; Banning, 2010: 75-77).

La producción artesanal también aumentó. Se multiplicaron los tipos de artefactos producidos y surgieron nuevas industrias, como por ejemplo la metalurgia. En lo que respecta a la producción cerámica, ya es posible detectar niveles de estandarización en algunas piezas, como por ejemplo los cuencos "en forma de V", algunas mantequeras y las denominadas "jarras torpedo" (torpedo jars) (Kerner, 2010: 186-189); en el caso de la industria lítica podemos mencionar el hallazgo de talleres de hoces de pedernal (cf. Gilead et al., 2010); por último, contamos también con la presencia de talleres metalúrgicos ubicados en diferentes sitios de la región de Beersheba (Golden, 2010: 35-47).

Este aumento de la producción, la aparición de nuevas industrias y la mayor especialización artesanal, se vieron acompañados también por un incremento de las interacciones entre las distintas regiones del Levante meridional. Milevski y Barzilai (2017: 33-37) sostienen que las redes de intercambio se volvieron más densas y regulares, destacando una red principal de recorrido longitudinal, paralela al valle del Jordán, y otras secundarias transversales (oeste-este y este-oeste), a través de las cuales circulaban principalmente objetos de pedernal, de basalto y de cobre. En el caso de estos últimos, por ejemplo, habría imperado una red longitudinal de dirección sur a norte, pues si bien los centros de producción se ubicaban en el valle de Beersheba, y quizás también en el desierto de Judea (cf. Goren, 2014: 263-265), 
3. Pero cabe mencionar que en otros sitios destinados a la interacción no se han podido hallar artefactos iconográficos, como por ejemplo en Palmahim Norte (Gorzalczany, 2007). En este último, como en otros sitios ubicados en el sur de la cultura Ghassuliense, lo que sí se ha podido hallar son, a lo sumo, estelas anicónicas, quizás el reflejo de una influencia meridional, pues guardaría mayor vinculación con las pautas que parecen haber caracterizado a la cultura Timnita. los objetos de cobre han sido hallados en sitios de la Alta Galilea y la costa mediterránea. Como vemos, estos artefactos, a pesar de haber sido elaborados en una determinada región, tuvieron una amplia circulación por todo el Levante meridional.

No es posible asegurar cuáles habrían sido las modalidades a partir de las cuales se concretaban estas interacciones, pero pudieron ser múltiples. Además del mero trueque podemos suponer que muchas habrían adoptado un carácter ceremonial, esto es, que la entrega de un bien por otro habría implicado el establecimiento de lazos y de obligaciones sociales (cf. Earle, 1982: 9; Hodder, 1982: 207-208). Sucede que parte importante de los bienes intercambiados parece haber poseído un alto valor simbólico, como las figurinas antropomorfas de hueso y de marfil, algunas vasijas de aparente función ritual, así como también los artefactos de cobre, posiblemente empleados como bienes de prestigio (Gopher y Tsuk, 1996: 236; Gal et al., 2011: 14; Drabsch y Bourke, 2014: 1095-1096).

De manera interesante, también se verifica un aumento en la cantidad de espacios físicos dedicados a la interacción social, lo mismo que los cementerios disociados de los poblados. El sitio de Gilat, en el norte del Néguev, posee una gran cantidad de bienes de origen foráneo, por lo que es probable se haya tratado de un lugar donde interactuaban grupos provenientes de diversas regiones (Levy, 2006). Ein Gedi, sitio ubicado en un promontorio con vista al mar Muerto, es posible que haya servido como un centro de peregrinación para poblaciones dispersas de la región del desierto de Judea (Ussishkin, 2014). Por su parte, el sitio de Tuleilat Ghassul, en el sur del valle del Jordán, posee un conjunto de estructuras que parece estaban destinadas a la reunión de diferentes familias que allí prestaban culto a una serie de deidades (Seaton, 2008: 169-170).

De igual forma, la difusión de la práctica del enterramiento secundario implicaba la realización periódica de rituales funerarios donde diferentes grupos parentales se habrían reunido a inhumar a los difuntos (Ilan y Rowan, 2012: 102-107; Nativ, 2013: 121-122; Shalem et al., 2013: 425-428; Winter-Livneh et al., 2012: 426-428). Aunque parece que muchos cementerios sólo correspondían a la población de las inmediaciones, en otros es posible que hayan involucrado personas procedentes de otras regiones, como indican por ejemplo los estudios petrográficos realizados en tiestos correspondientes a osarios de Nahal Qanah y de Peqi'in (Jaruf et al., 2014: 170).

Un rasgo compartido en todos estos espacios de interacción que merece ser destacado es la gran cantidad de artefactos iconográficos hallados en los mismos $^{3}$. En Gilat, por ejemplo, se han encontrado más de sesenta estatuillas de diferente estilo y material (Commenge et al., 2006). El sitio de Ein Gedi, además de poseer unas pocas estatuillas zoomorfas, es probable que haya sido el lugar donde se utilizaron los más de cuatrocientos objetos de cobre hallados en la cueva de Nahal Mishmar, ubicada a 15 km de distancia (Goren, 2014; Ussishkin, 2014). Cabe mencionar que estos objetos consisten en mazas piriformes, bastones y cilindros, entre otros, y que cuentan con una variada y rica iconografía (Bar-Adon, 1980). En el sitio de Tuleilat Ghassul, por su parte, además de las estatuillas, destacan los frescos ubicados al interior de diferentes 
estructuras (Cameron, 1981; Drabsch, 2015). Finalmente, en las mencionadas cuevas de enterramiento secundario de Nahal Qanah y de Peqi'in, además de una enorme variedad de osarios ricamente decorados, se han encontrado estatuillas y objetos de marfil, así como también artefactos de cobre, oro y electro (Gopher y Tsuk, 1996: 114-129; Shalem et al., 2013: 329-335).

\section{Motivos iconográficos comunes}

A pesar de la diversidad de objetos e imágenes mencionadas en la sección anterior, es posible identificar una serie de motivos comunes, lo que nos permite considerar de manera conjunta a las expresiones iconográficas de las culturas Ghassuliense y Golanita. En este trabajo hemos clasificado dichos motivos de la siguiente manera: la nariz prominente, el par de ojos, los senos, el ave y el pico de ave, y los cuernos y el animal enastado.

\section{El motivo de la nariz prominente}

Puede que el motivo de la nariz prominente haya sido el más extendido del período. Se halla en estatuillas de hueso, de marfil y de terracota (Fig. 2.13), en osarios (Fig. 3.1-5, 10-13) y vasijas cerámicas (Fig. 4.3-4), en pilares y cuencos de basalto (Fig. 5), y en objetos de cobre (Fig. 6.1). Suele estar acompañado de un par de ojos, aunque también se conocen ejemplos donde aparece solo (Perrot y Ladiray, 1980: Fig. 39; Epstein, 1998: Pl. XXXI.1; MischBrandl, 2014: Fig. 4.17).

En la mayoría de los casos se trata de una protuberancia ligeramente triangular. Puede estar tallada, como por ejemplo en las figurinas de marfil y en los pilares y cuencos de basalto. En otras ocasiones consiste en un fragmento de arcilla, el cual era adherido tanto en osarios como en vasijas cerámicas. De estas últimas se conoce un tipo particular de decoración, restringida a los Altos del Golán, al cual C. Epstein (1998: 170, Pl. XXVI) denominó como "asas en forma de ojos y de narices" (eye and nose handles) (Fig. 4.3). También conocemos ejemplos de lo que parecen ser narices pintadas, como en la fachada de dos osarios de Ben Shemen (Fig. 3.6-7).

De manera interesante, existen objetos en los que parece que se reprodujo más de una nariz. Un caso es un osario de Et-Taiyiba, en el cual figuran dos narices, una arriba de la otra: la superior pintada y la inferior esculpida (Fig. 3.12). De ser así, el hecho de que aparezcan varias en un mismo objeto podría ser indicio de que las mismas, en lugar de remitir al cuerpo en su totalidad, habrían tenido un significado independiente. De todas maneras, la calidad de la imagen publicada no nos permite asegurar que haya habido una nariz pintada, pues también podría llegar a interpretarse como un bigote.

Dicho esto, no es seguro que todas las narices prominentes fueran en realidad narices humanas. En el caso de los pilares de basalto, algunas fueron representadas de manera rectangular, con esquinas casi rectas (Fig. 5.1). Otras, en cambio, están proyectadas hacia arriba (Fig. 5.2). 
Algo parecido sucede en los osarios de cerámica. J. Perrot y D. Ladiray han señalado que algunas de las narices serían en realidad picos de aves (Perrot y Ladiray, 1980: Tab. X.a, d) u hocicos de mamíferos (Perrot y Ladiray, 1980: Tab. X.e). En el caso de los primeros, los ojos tienden a ser muy pequeños y pueden estar colocados a media altura las narices, lo que a todas luces no es un rasgo antropomorfo (Fig. 3.3). Que sean picos de aves explicaría, a nuestro entender, la desproporción de estos motivos.

\section{El motivo del par de ojos}

El par de ojos suele acompañar a la nariz prominente, aunque hay unos pocos casos en los que aparece sólo o junto a una boca, como en un objeto de cobre de Nahal Mishmar (Fig. 6.1). Existen distintas maneras de representar este motivo, pero todas ellas son esquemáticas.

Una forma consiste en pintar de color rojo un círculo exterior delgado y un punto interior pequeño (Fig. 2.1). El círculo exterior delimita su contorno, mientras que el punto representa la pupila. Un ejemplo son dos vasijas de Gilat, una antropomorfa y otra zoomorfa (Commenge et al., 2006: Fig. 15.1-6). Esta semejanza nos plantea el problema de saber si los ojos, cuando aparecen de manera aislada, eran de seres humanos o de animales. Por ejemplo, en el sitio de Peqi'in encontramos círculos sin puntos interiores, pintados tanto en osarios con aparente forma humana como animal (Fig. 3.2) (Shalem et al., 2013: Figs. 4.25.2, 4.25.5, 4.26, 4.41, 4.43, 4.47.1-4). Lo mismo sucede en el caso de las máscaras y de los seres fantásticos de las pinturas murales de Tuleilat Ghassul, los cuales están pintados de color negro y poseen una pupila de mayor tamaño (Fig. 7) (Drabsch, 2015: Figs. $49-52,56,61,65)$.

También es posible encontrar ojos pintados con cejas o pestañas, como en osarios de Azor, de Ben Shemen y de Peqi'in (Fig. 3.1) (cf. Perrot y Ladiray, 1980: Figs. 60.1, 109.3, 110.1, 118.1; Yannai y Porath, 2006: Oss. 13, 18, 19; Shalem et al., 2013: Figs. 4.38, 5.10.2). Otros poseen todo su interior pintado, como en Et-Taiyiba (Yannai y Porath, 2006: Oss. 15). En este último sitio contamos, además, con un ojo pintado compuesto por pequeños círculos concéntricos (Fig. 3.12).

Un motivo singular es aquel que parece poseer un ojo dentro de otro ojo, con pestañas por dentro y por fuera, como en osarios de Azor y de Peqi'in (Fig. 3.4) (cf. Perrot y Ladiray, 1980: Figs. 32.1, 33.1; Shalem et al., 2013: Fig. 4.114.4). Asimismo, hay ojos que tienen cruces dentro (Fig. 3.13) (cf. Yannai y Porath, 2006: Oss. 23; Shalem et al., 2013: Fig. 5.18-20), y otros donde su forma es tan esquemática que parece la de una estrella (Fig. 3.6).

Una manera distinta de representar los ojos es por medio de pequeñas cavidades circulares. Esto se verifica tanto en osarios como en jarras de enterramiento (Fig. 3.5, 9-10) (cf. Sukenik, 1937: Fig. 10, Pl. IV.2; Perrot y Ladiray, 1980: Figs. 48-9; Yannai y Porath, 2006: Oss. 5; Shalem et al., 2013: Figs. 4.14, 4.17.1, 4.28, 4.30.3, 4.50, 4.56, 4.59.1, 4.103). Otro tipo de cavidad, pero más grande, se halla en las estatuillas de hueso y de marfil, 
la cual es posible que estuviera ocupada de manera original por pequeños discos o bolitas (Fig. 2.3) (cf. Perrot, 1955: Pl. 2.a; Levy y Golden, 1996: 151).

De manera contraria, hay ojos que son representados en forma de pequeñas protuberancias, como por ejemplo en los pilares de basalto de los Altos del Golán (Fig. 5.1), y en los osarios de Et-Taiyiba y de Peqi'in (Fig. 3.3) (cf. Esptein, 1998: Pl. XXX.1-6, 8, 10, XXXII.1, XXXIII.1, 3, 5-6, 11, 13; Yannai y Porath, 2006: Oss. 20; Shalem et al., 2013: Figs. 4.9-10, 4.40.1, 4.64). En ocasiones, estas protuberancias adoptan la forma de pequeñas perillas, como en un osario de Shaar Efrayim (van den Brink, 2011: Fig. 25).

Por último, mencionamos unos pocos casos donde desde los ojos descienden líneas verticales rectas u onduladas, que al parecer representaban lágrimas. Además de la vasija antropomorfa de Gilat ya mencionada (Fig. 2.1), hay que sumar un osario de Et-Taiyiba (Yannai y Porath, 2006: Oss. 14), y un gran cuenco de pie de Peqi'in (Shalem et al., 2013: Fig. 5.18-20).

\section{El motivo de los senos}

Entre los motivos asociados a lo femenino, el más extendido son los senos. Aparecen en las estatuillas figurativas (Fig. 2.1-2) y esquemáticas (Fig. 2.4), así como en osarios (Fig. 3.1,3) y vasijas cerámicas (Fig. 4.4). Destaca su ausencia en los pilares de basalto, las pinturas murales y los artefactos de cobre.

Este motivo puede figurar solo (cf. Mallon et al., 1934: Fig. 34.2; Epstein, 1998: Pl. VI.3, XXI.7; Shalem et al., 2013: Fig. 9.2.1) o acompañado de una nariz prominente y de un par de ojos (cf. Perrot y Ladiray, 1980: Fig. 37; Porath, 2006: Fig. 14.1; van den Brink, 2011: Fig. 39; Shalem et al., 2013: Figs. 4.10, $4.14-15,4.20,4.31,4.113)$. En el caso de las estatuillas suele aparecer junto a una vulva (Fig. 2.1-2) (cf. Perrot, 1959: Fig. 1; Levy, 1986: 93; Commenge et al., 2006: Fig. 15.1-3).

Su forma de representación es esquemática, consistiendo básicamente en un par de protuberancias adheridas, esculpidas o talladas en forma de conos. Hay algunos de tamaño muy pequeño, como en dos jarritas y un cuenco con asas hallados en sitios de los Altos del Golán (Epstein, 1998: Pl. XV.7, XXI.68). Algunas vasijas pithoi de esta misma región poseen pares de pequeñas protuberancias en forma de perillas, que quizás también representaban senos (cf. Epstein, 1998: Pl. VI.3, XXVII.1-3). Ejemplos semejantes se han hallado en el sitio de Peqi'in (cf. Shalem et al., 2013: Fig. 4.131.2). En otros casos, en cambio, consisten en conos grandes y puntiagudos, los cuales en realidad pudieron haber sido colmillos, como en un osario de Azor (Perrot y Ladiray, 1980: Fig. 37), o picos de aves, como en un osario de Et-Taiyiba (Fig. 3.3).

Por último, conocemos dos osarios de Peqi'in que en lugar de tener senos esculpidos figuran sólo pintados (Shalem et al., 2013: Figs. 4.20-22). En un caso se trata de un dibujo donde desde dos grandes senos brota leche que cae sobre una superficie plana en la cual parecen crecer figuras semejantes a plantas (Fig. 3.1). 


\section{El motivo del ave y del pico de ave}

Este motivo zoomorfo cuenta con una importante presencia en la iconografía del Calcolítico. Se lo encuentra en osarios (Fig. 3.5) y vasijas cerámicas (Fig. 4.1, 5-6), en artefactos de cobre (Fig. 6.2, 4), y probablemente también en pilares de basalto (Fig. 5.2).

Entre las vasijas se han hallado piezas ornitomorfas, como por ejemplo en una cueva de Palmahim (Fig. 4.5). Se han encontrado además cestos de cerámica que poseen imágenes esculpidas de aves en sus bordes (Fig. 4.1). Las mismas están representadas de manera esquemática: poseen cuellos cortos, cabezas redondeadas, pequeños picos y colas en forma de abanico. Es probable que se haya tratado de aves de la familia de las colúmbidas.

En el caso de los objetos de cobre, disponemos de un cilindro que tiene una decoración semejante al del cesto mencionado (Fig. 6.4). Este objeto posee dos aves sobre su borde superior, una delante de la otra. El tamaño y la forma de sus cuerpos nos sugieren que también se trataba de colúmbidas. Lo mismo sucede en otro objeto de metal, pero con forma de cuerno, en el cual el ave está parada sobre una especie de pedestal (Bar-Adon, 1980: № 157).

Un tipo distinto de pájaro, posiblemente de la familia de los accipítridos, es el que se encuentra representado en un estandarte de cobre (Fig. 6.2). El mismo tiene una forma rectangular con un orificio en el medio, por el cual seguramente pasaba el bastón de madera que lo sostenía. La cabeza está adherida al frente y presenta dos hoyos en el lugar de sus ojos, además de un pico abierto. Las alas están desplegadas y decoradas con diseños en zig-zag.

Además de estas piezas contamos con imágenes aisladas de picos. Ya hemos mencionado la ambigüedad de ciertas narices, lo que las confunde con picos de aves (Perrot y Ladiray, 1980: Tab. X.a, d). En el caso de Peqiin, por ejemplo, contamos con un osario cuyo frente está decorado con una protuberancia puntiaguda ligeramente curvada hacia abajo, y con dos ojos muy pequeños justo encima de la misma, como es común entre las aves (Fig. 3.5). Varios frontones de osarios hallados en otros sitios también parecer estar decorados con ojos y picos de aves (cf. Perrot y Ladiray, 1980: Figs. 39, 49; Yannai y Porath, 2006: Oss. 20; Shalem et al., 2013: Figs. 4.14-15).

Por último, es posible que algunas narices de los pilares del Golán, en especial las más grandes o aquellas que aparecen proyectadas hacia arriba (Fig. 5.2), hayan sido también picos de aves (cf. Epstein, 1998: Pl. XXXI.5, 7, 11). De ser así, cabe destacar que algunas estarían combinadas con cuernos, relación que también está presente en las pinturas de Tuleilat Ghassul, en particular en las denominadas máscaras espectrales (Fig. 7.1) (cf. Drabsch, 2015: Figs. 49-52). $\mathrm{Al}$ respecto, cabe mencionar también el vestido de un personaje del fresco " $\mathrm{La}$ Procesión" el cual parece haber estado decorado con dos grandes alas (Fig. 7.3).

\section{El motivo de los cuernos y del animal enastado}

Otro motivo zoomorfo ampliamente representado en la iconografía del período son los cuernos y el animal enastado. Se lo encuentra en osarios 
(Fig. 3.6-11, 14) y vasijas cerámicas (Fig. 4.2, 6-7), en pilares de basalto (Fig. 5.1) y en artefactos de cobre (Fig. 6.3-6). Es probable que la mayoría fuera la representación de cuernos de animales salvajes, como íbices o gacelas, aunque en unos pocos casos puede ser que hayan sido de carneros o de vacunos domésticos.

Comenzando por las decoraciones aplicadas en cerámicas, podemos mencionar algunas jarras de los Altos del Golán, las cuales poseen "cabezas enastadas aplicadas" (applied horned head) (Fig. 4.2), así como también "asas en forma de cuernos" (horn handles) (Fig. 4.7). Las hay tanto de superficie lisa como con pequeñas incisiones horizontales (cf. Epstein, 1998: Pl. XXIII.5-7).

En relación con lo anterior, en el Santuario A de Tuleilat Ghassul se ha hallado un par de cuernos cortos y lisos de cerámica adheridos a una vasija (Seaton, 2008: Pl. 125). En el mismo sitio se encontró una pequeña cabeza esculpida de un animal enastado, la cual habría estado pegada a la parte interior de un cuenco (Koeppel et al., 1940: Pl. 97.20; Lee, 1973: 97, C631.r).

En el caso de los osarios decorados con cabezas enastadas y cuernos aislados sobresale el sitio de Quleh (Milevski, 2002). Por un lado, contamos con cabezas cuyos cuernos salen de la frente y se curvan hacia atrás en forma de medialuna. En muchos casos están marcados con pequeñas líneas horizontales, lo que podría considerarse como los anillos de crecimiento de los íbices. Por otro lado, hay cuernos cuyas marcas son diagonales, lo que sugiere podían estar retorcidos, tales como los de las gacelas. De manera interesante, estas decoraciones suelen aparecer en grupos de dos, tres o cuatro cabezas (Fig. 3.9). La mayoría posee ojos y bocas incisas.

Cabezas enastadas o pares de cuernos aislados aparecen también en osarios de Ben Shemen y de Shoham North (cf. Perrot y Ladiray, 1980: Figs. 85, 119; van den Brink, 2005: Figs. 4.9.2-3, 4.11.13). Entre estos últimos destaca un motivo singular, que consiste en una tira horizontal con incisiones verticales, sobre la cual se proyectan dos cuernos curvados hacia afuera (Fig. 3.14).

En otros casos aparecen dos pares de cuernos, pegados uno junto al otro (Fig. 3.11), o incluso tres pares, como en un osario de Ben Shemen (Perrot y Ladiray, 1980: Tab. X.2). En ocasiones se adhería una masa oval de terracota sobre la cual se hacían dos incisiones verticales, lo que provocaba que figurasen tres cuernos, motivo sin dudas fantástico (Fig. 3.8). También hay imágenes que consisten en la superposición de tres pares, resultado en la suma de seis cuernos (Fig. 3.7). Otros motivos fantásticos se hallan en Benei Beraq, donde hay un frontón con una nariz prominente y dos pares de cuernos a sus costados, uno a la derecha y otro a la izquierda (Perrot y Ladiray, 1980: Fig. 142). Una idea semejante figura en un osario de Shoham North (Fig. 3.10).

En lo que respecta a los pilares de basalto de los Altos del Golán, suelen poseer dos pequeños cuernos en su parte superior (Fig. 5.1). Una decoración parecida se identificó en un cuenco de basalto de esta misma región (Epstein, 1998: Pl. XXXVIII.10). 
Concentrándonos ahora en los objetos de cobre, podemos mencionar varios bastones y cilindros, los cuales cuentan tanto con cuernos como con cabezas enastadas. Un ejemplo es un bastón con cinco cabezas hallado en Nahal Mishmar (Fig. 6.5). Cuatro de ellas tienen cuernos largos curvados hacia atrás y con marcas horizontales, mientras que la restante tiene cuernos retorcidos lisos, quizás los de un antílope (Bar-Adon, 1980: 42), aunque es posible que fuera de un carnero, como el caso de un pendiente de peridotita hallado en Gilat (Commenge et al., 2006: Fig. 15.26). Otro bastón de cobre hallado en Giv’at Ha-Oranim muestra algunos paralelos con la pieza anteriormente descrita, pues posee cuatro cabezas con cuernos curvados como medialunas y de superficie ranurada (Fig. 6.6).

Pasando ahora a los cilindros de cobre, un ejemplo es la denominada "corona" no 7 de Nahal Mishmar, que tiene dos proyecciones rectangulares abiertas cuyos bordes están decorados con perillas o clavos y pares de cuernos, quizás de íbices o de gacelas (Fig. 6.4). Un fragmento trapezoidal hallado en Giv'at Ha-Oranim, quizás la parte de un cilindro, también está decorado con un par de cuernos (Namdar et al., 2004: Fig. 5.1.16). La "corona" no 8 de Nahal Mismar, por su parte, presenta cinco cuernos -dos de ellos hoy perdidos-, los cuales son cortos, curvos y lisos. Un motivo semejante decora una jarra de metal del mismo sitio (Bar-Adon, 1980: No 162).

Para el caso del motivo del animal enastado, podemos mencionar una cabeza de maza decorada de Nahal Mishmar, sobre la cual se proyectan dos íbices o gacelas unidas por sus lomos (Fig. 6.3). Animales parecidos figuran grabados en una vasija mortuoria hallada en la cueva 4 de Horbat Qarqar South (Fabian et al., 2015: Fig. 10.18). La misma posee cuatro animales enastados ubicados en fila, representados de manera muy esquemática, con las extremidades delanteras ligeramente arqueadas y el cuerpo inclinado, como si estuvieran saltando.

Algunos tiestos de Tuleilat Ghassul poseen decoraciones parecidas, pero con líneas puntuadas (Mallon et al., 1934: Fig. 61.1-3). Otros tiestos contienen pinturas de mamíferos enastados sobre los cuales se posan grandes aves (Fig. 4.6). Esta asociación entre animales con cuernos y aves se replica en las pinturas murales, donde contamos con un animal enastado que parece tener alas (Fig. 7.2). Asimismo, disponemos de máscaras que a veces tienen cuernos y otras proyecciones parecidas a picos (Fig. 7.1). En el caso de los objetos de cobre, ya hemos mencionado el cilindro decorado en sus bordes con dos aves (Fig. 6.4) y el artefacto con forma de cuerno con un pedestal sobre el cual se posa un pájaro (Bar-Adon, 1980: № 157).

\section{Variabilidad en la distribución de los motivos iconográficos}

\section{Diferencias regionales y tipológicas}

El repertorio de motivos iconográficos comunes descrito en la sección anterior, que caracteriza a todo el período Calcolítico en el Levante meridional, presenta sin embargo una distribución desigual. No sólo algunos motivos figuran más en unas regiones que en otras, sino que también están reproducidos en objetos de distinto tipo y material. 
En la costa mediterránea, el piedemonte contiguo y la Alta Galilea, el grueso de las decoraciones corresponden a osarios hallados al interior de cuevas de enterramiento secundario (Fig. 3). Pues bien, mientras que el motivo de los cuernos suele aparecer con frecuencia en las cuevas de la costa mediterránea y el piedemonte contiguo, como por ejemplo en Ben Shemen, Benei Beraq, Quleh y Horbat Qarqar South (Perrot y Ladiray, 1980; Milevski, 2002; Fabian et al., 2015), en la Alta Galilea está prácticamente ausente, donde por el contrario predomina el de los senos, como demuestra la evidencia del sitio de Peqi'in (Shalem et al., 2013).

Al este de la Alta Galilea, cruzando el río Jordán, se encuentra la región de los Altos del Golán, donde la mayoría los motivos decoran pilares de basalto (Fig. 5) y vasijas de cerámica (Fig. 4.2-4, 7). En estos objetos figuran la nariz prominente, el par de ojos y los cuernos, pero no así los senos, salvo por la posible excepción de dos jarritas (Epstein, 1998: Pl. XXI.6, 8), lo que contrasta con la región vecina de la Alta Galilea. ¿Puede ser, acaso, que la ausencia de cuernos en esta última región, y la extendida presencia de senos, se hubiera debido a que eran símbolos que servían como marcas de diferenciación con respecto a sus vecinos del este?

Otra región donde la presencia del motivo de los senos es muy baja es el valle meridional del Jordán, al sur del Golán. El único posible ejemplo son dos pequeñas protuberancias que decoran una vasija de cerámica (Mallon et al., 1934: Pl. 53). En esta región, y en particular en el sitio de Tuleilat Ghassul, los motivos figuran sobre todo en pinturas murales (Fig. 7). En ellas se reproducen también los motivos del par de ojos y de los cuernos, lo mismo que el de la nariz prominente, aunque es probable que en realidad se tratara de picos de aves, como parece sugerir la presencia de pinturas de máscaras con plumas, vestidos con alas y la representación figurativa de una gran ave (Drabsch, 2015: Figs. 48-52).

El motivo de los senos vuelve a aparecer en el norte del Néguev. Aquí figura sobre todo en estatuillas figurativas de cerámica y de marfil (Fig. 1.1-2) (cf. Perrot, 1955; 1959; Levy, 1986; Commenge et al., 2006: Figs. 15.1-3, 15.15-23). En lo que respecta a esta última región, es posible establecer una distinción entre la zona del valle de Grar-Besor y la de Beersheba. En la primera abundan las estatuillas de piedra esquemáticas y las figurativas de cerámica, donde destaca una femenina desnuda con los senos remarcados (Fig. 2.1). En el valle de Beersheba, en cambio, sobresalen las estatuillas figurativas de marfil (Fig. 2.2), a las que hay que sumar una cabeza de basalto (Levy y Alon, 1985: Fig. 4.1), así como también una estatuilla de cuerpo esquemático pero con rostro figurativo (Fig. 2.3).

Estas variables regionales, donde en cada zona predominaban artefactos disímiles -osarios de arcilla, pilares de basalto, pinturas murales, estatuillas esquemáticas o figurativas- quizás fueran la expresión de identidades locales, resultado de la persistencia de tradiciones previas. Aun así, merece destacar que, a pesar de estas diferencias, la mayoría compartían motivos iconográficos comunes, por lo que si bien por un lado habrían reflejado una identidad local, por el otro habrían expresado su vinculación con las demás regiones del 
Levante meridional. También es posible plantear que, en determinados casos, la preferencia de un motivo en lugar de otro, como parece indicar la extendida presencia de senos y la práctica ausencia de cuernos en la Alta Galilea, habría servido para fortalecer dichas identidades, en contraste a las demás poblaciones del sur del Levante con quienes interactuaban.

\section{Diferencias temporales y de soporte}

Algunas de las diferencias descritas en la sección anterior, además de regionales, pudieron haber sido también cronológicas. En el caso del norte del Néguev, por ejemplo, se puede diferenciar entre una fase temprana y otra tardía (Gilead, 2011: 19-20; Gilead y Gošić, 2014: 232). La primera corresponde, en mayor medida, a los sitios ubicados en el valle de Grar-Besor. Recordemos que aquí predominaban las estatuillas esquemáticas de piedra y las figurativas de cerámica. En la fase tardía, en cambio, la mayor cantidad de los sitios se ubican en torno al valle de Beersheba, donde las figurinas esquemáticas pasan a ocupar un segundo lugar, y las figurativas de cerámica son reemplazadas por ejemplares elaborados en marfil. A estos últimos se suman artefactos de cobre, tales como bastones y cabezas de maza piriformes (cf. Perrot, 1955: 25-26, 29, 34, 79; Eldar y Baumgarten, 1985: 135; Shalev y Northover, 1987: 358-359). Al respecto, cabe mencionar que estos objetos guardan una estrecha semejanza con aquellos hallados en Nahal Mishmar, en el desierto de Judea, donde destacan los motivos del ave, de los cuernos y del animal enastado (Fig. 6.1, 3-5). En efecto, en la región de Beersheba, junto a las figurinas antropomorfas de marfil, también se han hallado algunas con forma de aves (cf. Elliott, 1977: Fig. 4.5; Levy y Alon, 1992: Fig. 3).

Es interesante notar que si los objetos de cobre corresponden a una fase tardía al interior del Calcolítico, tampoco representaban de manera figurativa ni los cuerpos humanos ni los animales, sino que la mayoría reproducía sólo algunos rasgos de los mismos, como las narices y los cuernos. Este hecho ha llevado a dos investigadoras a plantear que la mayor parte de las semejanzas iconográficas se darían entre los objetos de cobre y los osarios de la costa (Merhav, 1993; Shalem, 2015), por lo que estos últimos también corresponderían a una fase tardía dentro del período. Podríamos agregar que el hecho de reproducir sólo parte del cuerpo, y de manera esquemática, habría favorecido que el motivo iconográfico adquiriera un significado independiente, pasando entonces quizás a formar parte de un corpus simbólico mayor.

De ser así, es menester señalar también que parte de los materiales empleados como soporte en esta fase tardía, a diferencia de los anteriores, eran de más difícil acceso. El marfil muy probablemente era de origen foráneo, quizás Egipto (Perrot, 1959: 17-18), mientras que el cobre era producido por un sector reducido de artesanos concentrado en una sola región, el valle de Beersheba (Golden, 2010: 35-47). Las estatuillas de piedra, de terracota y de cerámica, que habrían predominado en las fases más tempranas, estaban hechas con materiales de mayor disponibilidad y por un sector más amplio de artesanos. No obstante, cabe hacer una salvedad en el caso de algunas piedras, como por ejemplo el basalto y otras piedras procedentes del sur del Néguev y del Sinaí, tales como el esquisto, la filita y la granodiorita, con los cuales se hicieron 
algunas figurinas esquemáticas (Commenge et al., 2006: 751 y ss.). Muchos de estos objetos se encuentran en el sitio de Gilat, que se supone habría sido un centro de intercambio, posibilidad favorecida por el hallazgo también de una cabeza de mamífero enastada, ya mencionada, hecha en peridotita y quizás procedente de Anatolia.

No obstante, en la fase tardía del Calcolítico aumentó el empleo de materiales más exóticos. Al mismo tiempo, la complejidad de determinados artefactos, en especial los de metal, dan cuenta de que eran resultado de la aplicación de un saber técnico especializado, correlativo del proceso de división social del trabajo ya enunciado. Es posible pensar, por lo tanto, que estos nuevos objetos, además de replicar un repertorio iconográfico común anterior, denotarían ahora un acceso a un tipo de material o de producción fuera del alcance de la mayoría de la población. En definitiva, la circulación de objetos de cobre y de marfil podría haber fortalecido las vinculaciones interregionales, pero al costo de ir restringiéndola a los grupos que sí podían acceder a este tipo de bienes.

\section{Conclusión}

Uno de los rasgos característicos de las culturas calcolíticas del Levante meridional es el aumento de sus expresiones iconográficas. Para explicar este fenómeno hemos decidido analizar el conjunto de la evidencia a partir del concepto de esferas de interacción, esto es, como una de red de vinculaciones en las cuales el intercambio de bienes era favorecido por la existencia de un código simbólico común, donde las identidades de quienes participaban se definían en interacción con lo local y lo foráneo, y donde se encontraban involucrados también procesos de jerarquización social.

En el comienzo establecimos el contexto socioeconómico del período. Vimos que a partir de mediados del $\mathrm{V}^{\circ}$ milenio a.C., el crecimiento poblacional, el aumento en la producción y la intensificación de la especialización, en especial con el surgimiento de la metalurgia, implicaron un incremento en la división social del trabajo, lo que dio lugar a un aumento de las interacciones entre las distintas regiones del Levante meridional. Al respecto, remarcamos la multiplicación de espacios físicos dedicados a la interacción social, como los sitios de Gilat, Ein Gedi y Tuleilat Ghassul, así como también algunas cuevas de enterramiento secundario, en especial Nahal Qanah y Peqiin.

A continuación, procedimos a analizar la evidencia iconográfica. Primero, determinamos los motivos comunes de las culturas Ghassuliense y Golanita, concentrándonos en: la nariz prominente, el par de ojos, los senos, las aves y picos de aves, y los cuernos y los animales enastados. A nuestro entender, es posible que estos motivos hayan constituido un repertorio simbólico compartido merced al cual las poblaciones ubicadas en distintas regiones del Levante meridional lograron interactuar.

Segundo, destacamos que a pesar de estas semejanzas existían variables regionales significativas, no sólo en la preferencia de un motivo sobre otro, sino en 
especial en el tipo de objeto y material sobre el cual se escogía reproducirlos. Un ejemplo es el motivo de los senos, el cual si bien abunda en los osarios de la Alta Galilea, prácticamente está ausente tanto en los osarios de la costa mediterránea y del piedemonte contiguo, como en las vasijas cerámicas y los pilares de basalto de los Altos del Golán. Según el concepto de esferas de interacción aquí empleado, es posible que estas variables respondan a adaptaciones locales de un repertorio simbólico común, por lo que, si bien en un plano reconocen una semejanza, lo que favorecía el establecimiento de una relación mutua, en otro se diferenciaban enfatizando lo local en contraposición a lo foráneo.

Tercero, y último, dimos cuenta como en la fase tardía del Calcolítico los motivos iconográficos comenzaron a reproducirse en objetos de acceso más restringido, ya sea porque estaban elaborados con un material procedente de largas distancias, como el marfil, o porque eran producto de un trabajo más especializado, como los objetos de cobre. A nuestro modo de ver, este fenómeno también puede hallar una explicación a partir del concepto de esferas de interacción, pues el código simbólico común pudo haber sido acaparado paulatinamente por las elites aldeanas, y de esta manera pasar a denotar también una mayor posición de estatus.

Por supuesto que la lectura ofrecida aquí no pretende agotar la problemática de las expresiones iconográficas del Calcolítico en el Levante meridional, sino simplemente iluminar un aspecto que permita alcanzar una mejor comprensión de la posible función de las imágenes del período. Es decir, que más allá de los significados que las personas les debieron haber atribuido a cada una de ellas, todas en conjunto pudieron haber desempeñado una función social común: la de cimentar las vinculaciones entre las distintas regiones y con esto favorecer el intercambio interregional.

Como reflexión final, no deja de llamar la atención el hecho de que en torno al $3800 / 3600$ a.C. estas expresiones se hayan visto interrumpidas, sin tener una continuidad en la subsiguiente Edad del Bronce Antiguo I (cf. Yekutieli, 2014). Más llamativo resulta aún si consideramos que las interacciones interregionales continuaron aumentando, sobrepasando ahora la propia región del Levante meridional (cf. Klimscha, 2011). Ante este nueva situación podrían sugerirse distintos escenarios: un cambio en la población, un cambio en la naturaleza del intercambio, más enfocada en su aspecto utilitario, o bien una transformación del código común que lo sustentaba, donde los motivos iconográficos fueron reemplazados por símbolos que no dejaron ningún tipo de registro material. De una u otra manera, el final del período Calcolítico parece haber implicado también el final de una forma de practicar el intercambio.

\section{Agradecimientos}

Este artículo es una adaptación de una monografía presentada para el seminario de doctorado "Esferas de interacción e intercambio en la Prehistoria Tardía del Cercano Oriente: economía y sociedad", dictado durante el año 2015 por los Dres. Ianir Milevski (Autoridad de Antigüedades, Israel) y Bernardo Gandulla 
(Universidad de Buenos Aires) en la Facultad de Filosofía y Letras de la Universidad de Buenos Aires. Quisiera agradecer de manera especial a Amir Gorzalczany, de la Autoridad de Antigüedades de Israel, por sus comentarios y sugerencias sobre la versión preparada para esta publicación. De la misma institución agradezco a Ehud Galili, a Nimrod Getzov, a Hamoudy Khalaily, y a Alla Yaroshevich, como así también a Liora K. Horwitz, de la Universidad Hebrea de Jerusalén, y a Ofer Marder, de la Universidad Ben-Gurión del Norte del Néguev, quienes me permitieron en su momento tener acceso a información todavía no publicada. Por último, agradezco a Daniela Bruno y Verónica Silva, de la Universidad de Buenos Aires, por sus críticas y observaciones. Cabe aclarar que todos los errores $u$ omisiones son de mi entera responsabilidad. 


\section{Q Bibliografía}

"Amiran, R. (1986). A New Type of Chalcolithic Ritual Vessel and Some Implications for the Nahal Mishmar Hoard, en: Bulletin of the American Schools of Oriental Research 262: 83-87.

»Asouti, E. (2006). Beyond the Pre-Pottery Neolithic B Interaction Sphere, en: Journal of World Prehistory 20: 87-126.

»Banning, E. B. (2010). Houses, Households, and Changing Society in the Late Neolithic and Chalcolithic of the Southern Levant, en: Paléorient 36: 49-87.

» Bar-Adon, P. (1980). The Cave of the Treasure. Jerusalén, Israel Exploration Society.

»Bar-Yosef, O. y Belfer-Cohen, A. (1989). The Levantine 'PPNB' Interaction Sphere", en: Hershkovitz, I. (ed.), People and Culture Change. Proceedings of the Second Symposium on Upper Paleolithic, Mesolithic and Neolithic Populations of Europe and the Mediterranean Basin. Oxford, Archaeopress: 59-72.

» Beck, P. (1989). Notes on the Style and Iconography of the Chalcolithic Hoard from Nahal Mishmar, en: Leonard Jr., A. y Williams, B. B. (eds.), Essays in Ancient Civilization Presented to Helene J. Kantor. Chicago, The Oriental Institute of the University of Chicago: 39-54.

» Bourke, S. (2008). The Chalcolithic Period, en: Adams, R. B. (ed.), Jordan: An Archaeological Reader. Londres, Equinox: 109-160.

»Caldwell, J. R. (1964). Interaction Spheres in Prehistory, en: Caldwell, J. R. y Hall, R. L. (eds.), Hopewellian Studies. Springfield, Illinois State Museum: 133-143.

"Cameron, D. O. (1981). The Ghassulian Wall Paintings. Londres, Kenyon-Deane.

»Commenge, C., Levy, T. E., Alon, D. y Kansa, E. (2006). Gilat's Figurines: Exploring the Social and Symbolic Dimensions of Representation, en: Levy, T. E. (ed.), Archaeology, Anthropology and Cult: The Sanctuary at Gilat, Israel. Londres, Equinox: 739-830.

"Drabsch, B. (2015). The Mysterious Wall Paintings of Teleilat Ghassul, Jordan, in Context. Oxford, Archaeopress.

»Drabsch, B. y Bourke, S. (2014). Ritual, Art and Society in the Levantine Chalcolithic: The 'Processional' Wall Painting from Teleilat Ghassul, en: Antiquity 88: 1081-1098.

»Earle, T. K. (1982). Prehistory Economics and the Archaeology of Exchange, en: Ericson, J. E. y Earle, T. K. (eds.), Contexts for Prehistoric Exchange. Nueva York, Academic Press: 1-12.

»Eldar, I. y Baumgarten, Y. (1985). Neve Noy, a Chalcolithic Site of the Beer Sheba Culture, en: Biblical Archaeologist 48: 134-139.

»Elliott, C. (1977). The Religious Beliefs of the Ghassulians C. 4000-3000 B.C., en: Palestine Exploration Quarterly 109: 3-25.

»Epstein, C. (1978). Aspects of Symbolism in Chalcolithic Palestine, en: Moorey, P. R. S. y Parr, P. J. (eds.), Archaeology in the Levant: Essays for Kathleen Kenyon. Warminster, Avis \& Phillips: 23-35. 
»Epstein, C. (1982). Cult Symbols in Chalcolithic Palestine, en: Bollettino del Centro Camuno di Studi Preistorici 19: 63-82.

"Epstein, C. (1998). The Chalcolithic Culture of the Golan. Jerusalén, Israel Antiquities Authority.

» Fabian, P., Scheftelowitz, N. y Gilead, I. (2015). Horvat Qarqar South: Report on a Chalcolithic Cemetery near Qiryat Gat, Israel, en: Israel Exploration Journal 65: 1-30.

» Gal, Z., Shalem, D., y Smithline, H. (2011). The Peqi'in Cave: a Chalcolithic Cemetery in Upper Galilee, Israel, en: Near Eastern Archaeology 74: 196-206.

»Gandulla, B. (2005). Los hebreos en el Gran Canaán. Buenos Aires, Editorial Canaán.

» Garfinkel, Y. (1999). Neolithic and Chalcolithic Pottery of the Southern Levant. Jerusalén, The Hebrew University of Jerusalem.

" Garfinkel, Y. (2014). The Levant in the Pottery Neolithic and Chalcolithic Periods, en: Renfrew, C. y Bahn, P. (eds.), The Cambridge World Prehistory. Volume 3: West and Central Asia and Europe. Cambridge, Cambridge University Press: 14391461.

» Gilead, I. (2011). Chalcolithic Culture History: Ghassulian and Other Entities in the Southern Levant, en: Lovell, J. L. y Rowan, Y. M. (eds.), Culture, Chronology and the Chalcolithic: Theory and Transition. Oxford, Oxbow Books: 12-24.

" Gilead, I. y Gošić, M. (2014). Fifty Years Later: A Critical Review of the Stratigraphy, Chronology and Context of the Nahal Mishmar Hoard, en: Mitekufat Haeven Journal of the Israel Prehistoric Society 44: 226-239.

» Gilead, I., Davidzon, A. y Vardi, J. (2010). The Ghassulian Sickle Blades Workshop of Beit Eshel, Beer Sheva, Israel”, en: Eriksen, B. V. (ed.), Lithic Technology in Metal Using Societies. Proceedings of a UISPP Workshop, Lisbon, September 2006. Højbjerg, Jutland Archaeological Society: 221-230.

"Golden, J. (2010). Dawn of the Metal Age: Technology and Society during the Levantine Chalcolithic. Londres, Equinox.

»Gopher, A. y Tsuk, T. (1996). The Nahal Qanah Cave. Earliest Gold in the Southern Levant. Tel Aviv, Tel Aviv University.

"Goren, Y. (2014). Gods, Caves, and Scholars: Chalcolithic Cult and Metallurgy in the Judean Desert, en: Near Eastern Archaeology 77: 260-266.

"Gorzalczany, A. (2007). Centro y periferia en el antiguo Israel: nuevas aproximaciones a las prácticas funerarias del Calcolítico en la planicie costera, en: Antiguo Oriente 5: 205-230.

»Hodder, I. (1982). Toward a Contextual Approach to Prehistoric Exchange, en: Ericson, J. E. y Earle, T. K. (eds.), Contexts for Prehistoric Exchange. Nueva York, Academic Press: 199-211.

» Ilan, D. y Rowan, Y. M. (2012). Deconstructing and Recomposing the Narrative of Spiritual Life in the Chalcolithic of the Southern Levant (4500-360o B.C.E.), en: Rowan, Y. M. (ed.), Beyond Belief: the Archaeology of Religion and Ritual. Hoboken (NJ), Wiley-Blackwell: 89-113.

"Jaruf, P. F., Gandulla, B. y Milevski, I. (2014). La estructura social del Calcolítico palestinense: una propuesta de interpretación desde el materialismo histórico, en: Antiguo Oriente 12: 149-184. 
»Kerner, S. (2010). Craft Specialization and its Relation with Social Organization in the Late $6^{\text {th }}$ to Early $4^{\text {th }}$ Millennium BCE of the Southern Levant, en: Paléorient 36: 179-198.

» Klimscha, F. (2011). Long-Range Contacts in the Late Chalcolithic of the Southern Levant. Excavations at Tell Hujayrat al-Ghuzlan and Tall al-Magass near Aqaba, Jordan, en: Mynárova, J. (ed.), Egypt and the Near East - The Crossroads. Proceedings of an International Conference on the Relations of Egypt and the Near East in the Bronze Age, Prague, September 1-3, 2010. Praga, Charles University in Prague, Faculty of Arts: 177-209.

» Koeppel, R., Senes, H., Murphy, J. y Mahan, J. (1940). Teleilat Ghassul II, 1932-1936. Roma, Institut Biblique Pontificial.

» Lee, R. (1973). Chalcolithic Ghassul. New Aspects and Master Typology. Jerusalén, Hebrew University.

»Levy, T. E. (1986). Archaeological Sources for the History of Palestine: the Chalcolithic Period, en: Biblical Archaeologist 49: 83-108.

»Levy, T. E. (1995). Cult, Metallurgy and Rank Societies - Chalcolithic Period (ca. 4500-3500 BCE), en: Levy, T. E. (ed.), The Archaeology of Society in the Holy Land. Londres, Leicester University Press: 226-244.

»Levy, T. E. (2006). Archaeology, Anthropology and Cult: Exploring Religion in Formative Middle Range Societies, en: Levy, T. E. (ed.), Archaeology, Anthropology and Cult. The Sanctuary at Gilat, Israel. Londres, Equinox: 4-33

»Levy, T. E. (2014). Cultural Transformations: the Chalcolithic Southern Levant, en: Sebbane, M., Misch-Brandl, O. y Master, D. M. (eds.), Masters of Fire: Copper Age Art from Israel. Nueva York / Princeton, Institute for the Study of the Ancient World at New York University / Princeton University Press: 40-60.

» Levy, T. E. y Alon, D. (1985). Shiqmim: a Chalcolithic Village and Mortuary Centre in the Northern Negev, en: Paléorient 11: 71-83.

» Levy, T. E. y Alon, D. (1992). A Corpus of Ivories from Shiqmim, en: Eretz Israel 23: 65-71 (en hebreo).

"Levy, T. E. y Golden, J. (1996). Syncretistic and Mnemonic Dimensions of Chalcolithic Art, en: Biblical Archaeologist 59: 150-159.

»Lovell, J. L. (2001). The Late Neolithic and Chalcolithic Periods in the Southern Levant. New Data from the Site of Teleilat Ghassul, Jordan. Oxford, Archaeopress.

» Mallon, A., Koeppel, R. y Neuville, R. (1934). Teleilat Ghassul I, 1929-32. Roma, Pontificial Biblical Institute.

" Merhav, R. (1993). Scepters of the Divine from the Cave of the Treasure at Nahal Mishmar, en: Heltzer, M., Segal, A. y Kaufman, D. (eds.), Studies in the Archaeology and History of Ancient Israel in Honor of Moshe Dothan. Haifa, Haifa University Press: 21-42 (en hebreo).

» Milevski, I. (2002). A New Fertility Figurine and New Animal Motifs from the Chalcolithic in the Southern Levant: Finds from Cave K-1 at Quleh, Israel, en: Paléorient 28: 133-142.

»Milevski, I. (2010). Visual Expressions of Craft Production in the Chalcolithic of the Southern Levant, en: Matthiae, P., Pinnock, F., Nigro, L. y Marchetti, N. (eds.), Proceedings of the $6^{\text {th }}$ International Congress on the Archaeology of the Ancient Near East, vol. 3. Wiesbaden, Harrassowitz Verlag: 423-430. 
»Milevski, I. (2013). The Transition from the Chalcolithic to the Early Bronze Age of the Southern Levant in Socio-Economic Context, en: Paléorient 39: 193-208.

» Milevski, I. y Barzilai, O. (2017). Redes de intercambio en los finales de la Prehistoria del Levante meridional, en: Milevski, I., Monti, L. y Jaruf, P. (eds.), Si un Hombre desde el Sur... / Šumma Awïlum ina Šūtim...: Escritos de Alumnos, Colegas y Amigos en Homenaje a Bernardo Gandulla, tomo 1. Buenos Aires, Facultad de Filosofía y Letras, Universidad de Buenos Aires: 23-56.

»Milevski, I. y Gandulla, B. (2014). Minor Arts and Society in the Chalcolithic of the Southern Levant, en: Bieliński, P., Gawlikowski, M., Koliński, R., Ławecka, D., Soltysiak, A. y Wygnańska, Z. (eds.), Proceedings of the $8^{\text {th }}$ International Congress on the Archaeology of the Ancient Near East, vol. 1. Wiesbaden, Harrassowitz Verlag: 489-503.

» Milevski, I., Getzov, N., Galili, E., Yaroshevich, A. y Horwitz, L. K. (2016). Iconographic Motifs from the 6th-sth Millennia BC in the Levant and Mesopotamia: Clues for Cultural Connections and the Existence of an Interaction Sphere, en: Paléorient 42: 135-149.

» Misch-Brandl, O. (2014). Spiritual Life in the Southern Levant during the Late Chalcolithic Period, 4500-3600 BCE, en: Sebbane, M., Misch-Brandl, O. y Master, D. M. (eds.), Masters of Fire. Copper Age Art from Israel. Nueva York / Princeton, Institute for the Study of the Ancient World at New York University / Princeton University Press: 78-99.

» Moorey, P. R. S. (1988). The Chalcolithic Hoard from Nahal Mishmar, Israel, in Context, en: World Archaeology 20: 171-189.

»Namdar, D., Segal, I., Goren, Y. y Shalev, S. (2004). Chalcolithic Copper Artefacts, en: Scheftelowitz, N. y Oren, R. (eds.), Giv'at Ha-Oranim. A Chalcolithic Site. Tel Aviv, Tel Aviv University: 70-83.

"Nativ, A. (2013). Prioritizing Death and Society. The Archaeology of Chalcolithic and Contemporary Cemeteries in the Southern Levant. Durham, Acumen.

"Perrot, J. (1955). The Excavations at Tell Abu Matar, near Beersheba", en: Israel Exploration Journal 5: 17-40, 73-84, 167-189.

» Perrot, J. (1959). Statuettes en ivoire et autres objets en ivoire et en os provenant des gisements préhistoriques de la région de Beersheba, en: Syria 36: 8-19.

"Perrot, J. y Ladiray, D. (1980). Tombes à ossuaires de la région côtière Palestinienne au IVe millénaire avant lère chrétienne. París, Association Paléorient.

"Porath, Y. (2006). Chalcolithic Burial Sites at Ma'abarot and Tel Ifshar, en: 'Atiqot 53: 45-63.

» Rosen, S. A. (2017). Revolutions in the Desert. The Rise of Mobile Pastoralism in the Southern Levant. Londres, Routledge.

» Rowan, Y. M. (2014). The Southern Levant (Cisjordan) during the Chalcolithic Period, en: Steiner, M. L. y Killebrew, A. E. (eds.), The Oxford Handbook of the Archaeology of the Levant, c. 8000-332 BCE. Oxford, Oxford University Press: 223236.

"Rowan, Y. M. y Golden, J. (2009). The Chalcolithic Period of the Southern Levant: a Synthetic Review, en: Journal of World Prehistory 22: 1-92.

"Seaton, P. (2008). Chalcolithic Cult and Risk Management at Teleilat Ghassul: the Area E Sanctuary. Oxford, Archaeopress. 
»Shalem, D. (2014). Imagery in the Chalolithic Period, en: Sebbane, M., MischBrandl, O. y Master, D. M. (eds.), Masters of Fire: Copper Age Art from Israel. Nueva York / Princeton, Institute for the Study of the Ancient World at New York University / Princeton University Press: 62-76.

»Shalem, D. (2015). Motifs on the Nahal Mishmar Hoard and the Ossuaries: Comparative Observations and Interpretations, en: Mitekufat Haeven - Journal of the Israel Prehistoric Society 45: 217-237.

» Shalem, D., Gal, Z. y Smithline, H. (eds.) (2013). Peqi'in. A Chalcolithic Burial Site, Upper Galilee, Israel. Jerusalén, Ostracon.

"Shalev, S. y Northover, P. J. (1987). Chalcolithic Metal and Metallurgy from Shiqmim, en: Levy, T. E. (ed.), Shiqmim I: Studies Concerning Chalcolithic Societies in the Northern Negev Desert, Israel. Oxford, Archaeopress: 357-371.

»Stein, G. J. (2010). Local Identities and Interaction Spheres: Modeling Regional Variation in the Ubaid Horizon, en: Carter, R. A. y Philip, G. (eds.), Beyond the Ubaid. Transformation and Integration in the Late Prehistoric Societies of the Middle East. Chicago, The Oriental Institute of the University of Chicago: 23-44.

»Sukenik, E. L. (1937). A Chalcolithic Necropolis at Hederah, en: Journal of the Palestine Oriental Society 17: 15-30.

"Tadmor, M. (1986). Naturalistic Depictions in the Gilat Sculptured Vessels, The Israel Museum Journal 5: 7-12.

»Ussishkin, D. (2014). The Chalcolithic Temple in Ein Gedi: Fifty Years after its Discovery, en: Near Eastern Archaeology 77: 15-26.

" van den Brink, E. C. M. (2005). The Ceramic Ossuaries, en: van den Brink, E. C. M. y Gophna, R. (eds.), Shoham (North). Late Chalcolithic Burial Caves in the Lod Valley, Israel. Jerusalén, Israel Antiquities Authority: 27-46.

» van den Brink, E. C. M. (2011). A Chalcolithic and Early Bronze Age I Burial Ground near Sha'ar Efrayim in the Sharon Plain, en: 'Atiqot 66: 1-53.

»Winter-Livneh, R., Svoray, T. y Gilead, I. (2010). Settlement Patterns, Social Complexity and Agricultural Strategies during the Chalcolithic Period in the Northern Negev, Israel, en: Journal of Archaeological Science 37: 284-294.

»Winter-Livneh, R., Svoray, T. y Gilead, I. (2012). Secondary Burial Cemeteries, Visibility and Land Tenure: a View from the Southern Levant Chalcolithic Period, en: Journal of Anthropological Archaeology 31: 423-438.

» Yannai, E. y Porath, Y. (2006). A Chalcolithic Burial Cave at Et-Taiyiba, en: 'Atiqot 53: 1-44.

"Yekutieli, Y. (2014). The Early Bronze Age Southern Levant: The Ideology of an Aniconic Reformation, en: Knapp, B. y van Dommelen, P. (eds.), The Cambridge Prehistory of the Bronze and Iron Age Mediterranean. Cambridge, Cambridge University Press: 609-618.

» Yoffee, N. (1993). Mesopotamian Interaction Spheres, en: Yoffee, N. y Clark, J. J. (ed.), Early Stages in the Evolution of Mesopotamian Civilization: Soviet Excavations in Northern Iraq. Tucson (AZ), The University of Arizona Press: 257-269. 


\section{Figuras}

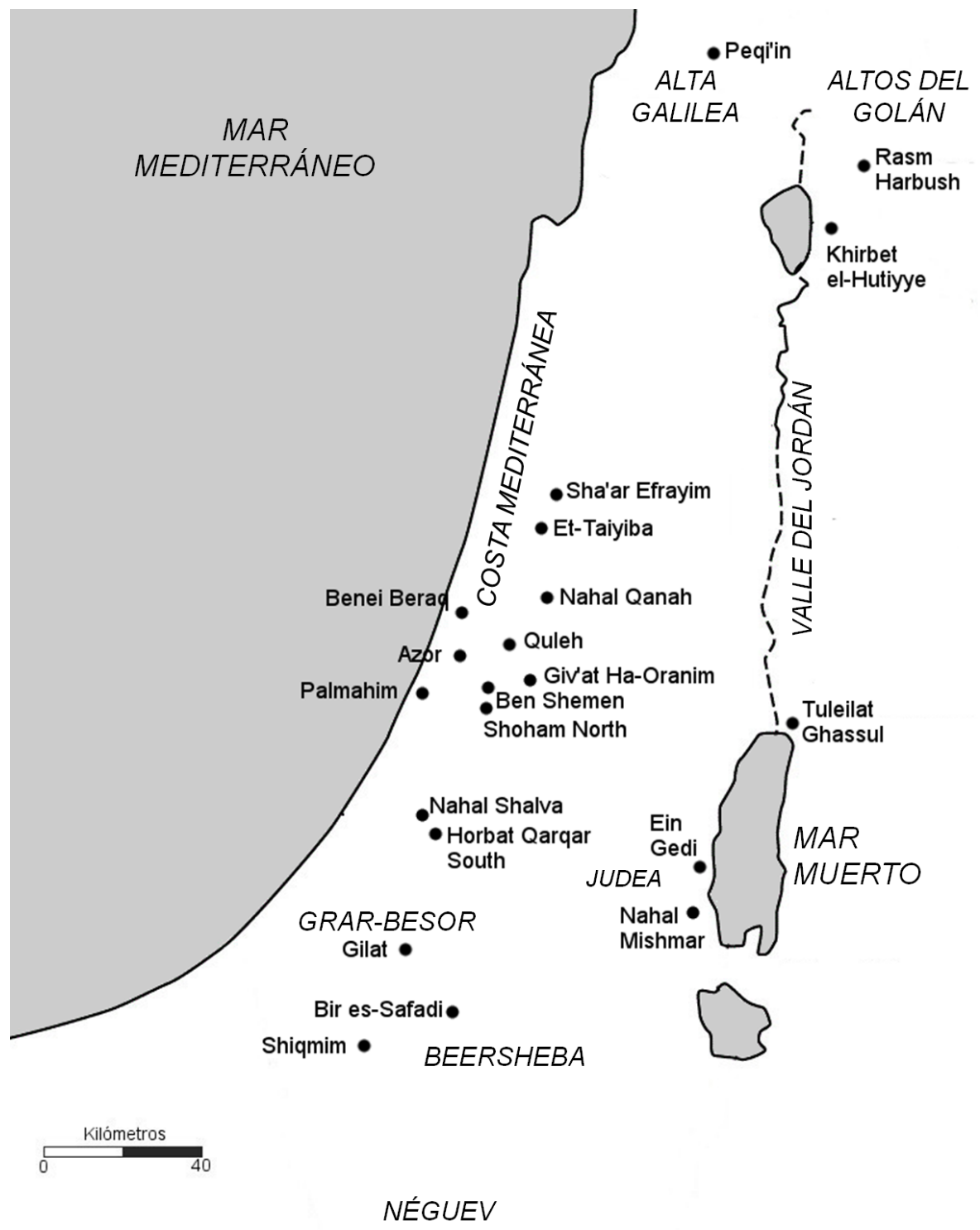

Fig. 1 Mapa del Levante meridional con las principales regiones y sitios mencionados en el texto (diseño propio) 

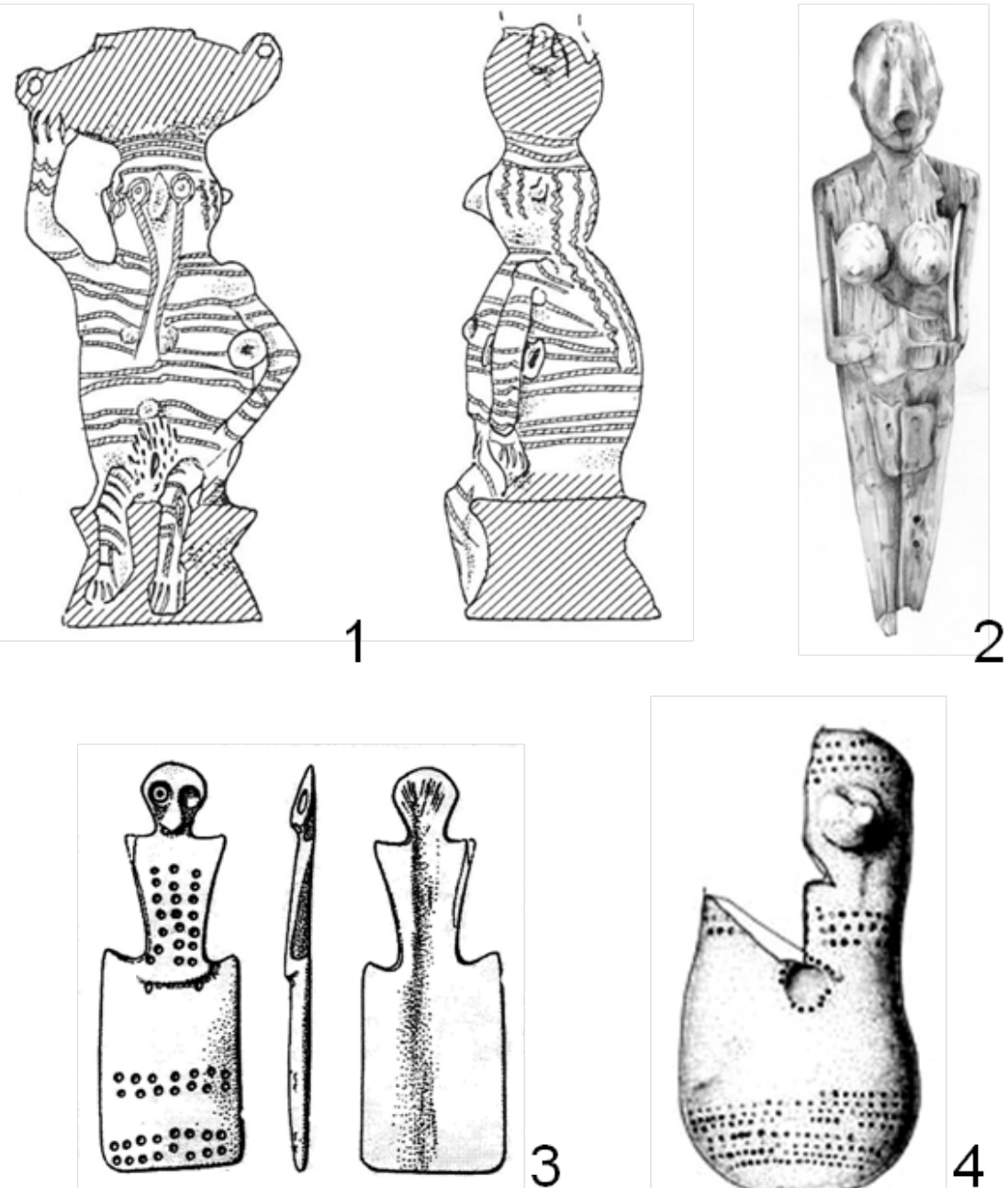

3

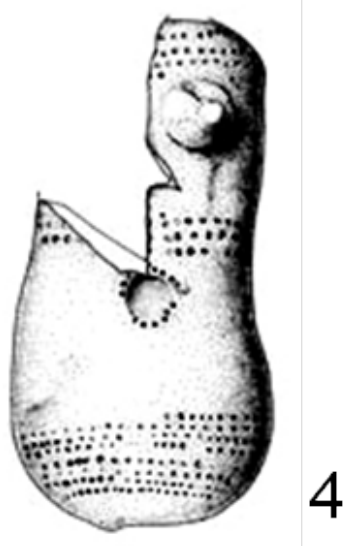

Fig. 2 Estatuillas figurativas y esquemáticas

2.1 Estatuilla figurativa de cerámica, Gilat (adaptado de Garfinkel, 1999: Fig. 165)

2.2 Estatuilla figurativa de marfil, Bir es-Safadi (adaptado de Drabsch, 2015: Fig. 39)

2.3 Estatuilla esquemática de hueso, Shiqmim (adaptado de Levy y Golden, 1995: 151)

2.4 Estatuilla esquemática de terracota, Nahal Shalva (cortesía de lanir Milevski) 

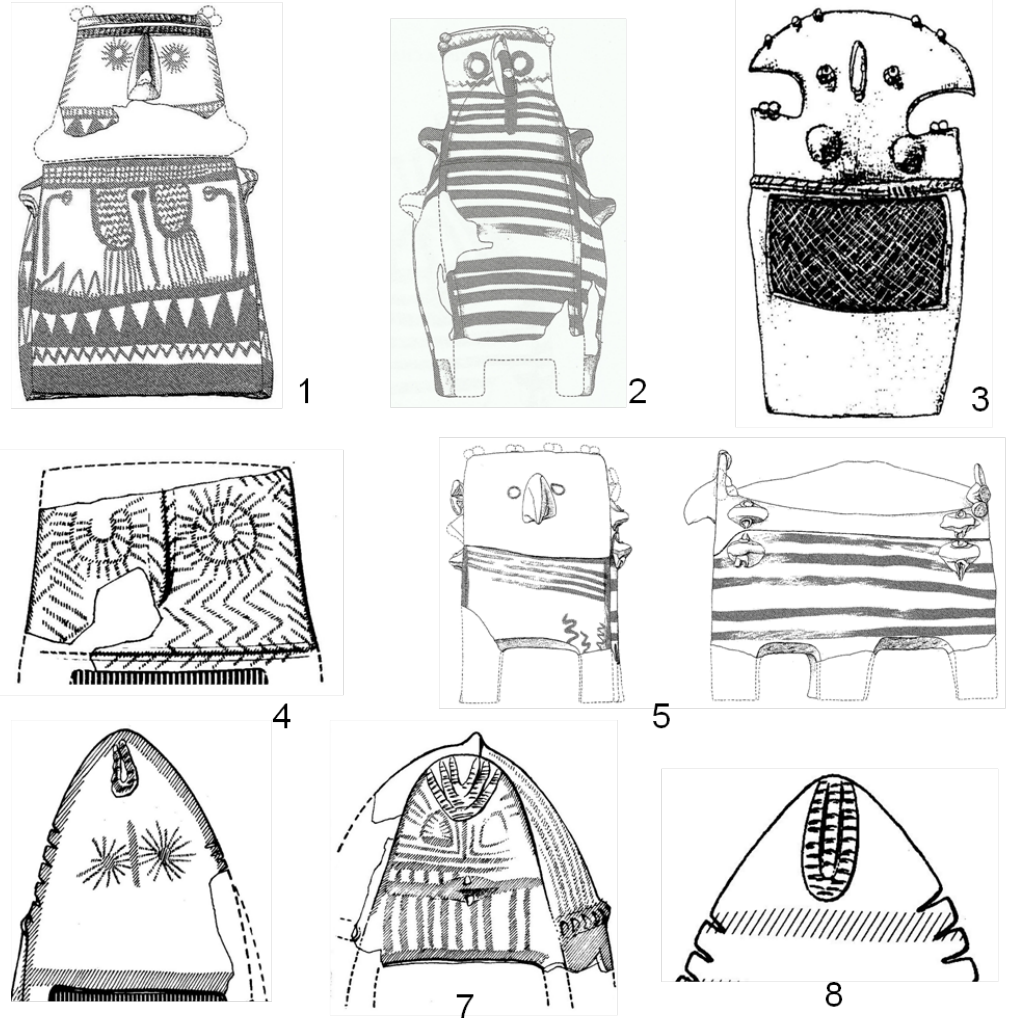

6
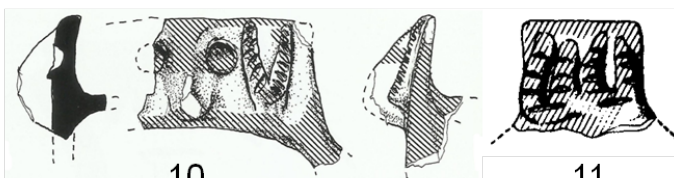

11

9

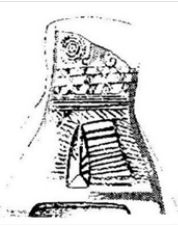

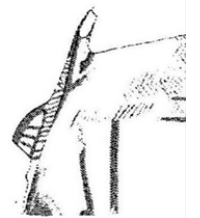

12

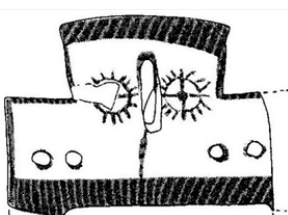

13

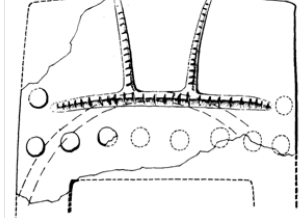

14

Fig. 3 Osarios de cerámica

3.1 Frente de osario, Peqi'in (adaptado de Shalem et al., 2013: Fig. 4.20)

3.2 Frente de osario, Peqi'in (adaptado de Shalem et al., 2013: Fig. 4.41)

3.3 Frente de osario, Et-Taiyiba (adaptado de Yannai y Porath, 2006: Oss. 20)

3.4 Frente superior de osario, Azor (adaptado de Perrot y Ladiray, 1980: Fig. 33.1)

3.5 Frente y costado izquierdo de osario, Peqi'in (adaptado de Shalem et al., 2013: Fig. 4.50-51)

3.6 Frente superior de osario, Ben Shemen (adaptado de Perrot y Ladiray, 1980: Fig. 93)

3.7 Frente superior de osario, Ben Shemen (adaptado de Perrot y Ladiray, 1980: Fig. 106)

3.8 Frente superior de osario, Ben Shemen (adaptado de Perrot y Ladiray, 1980: Fig. 104)

3.9 Frente superior de osario, Quleh (cortesía de lanir Milevski)

3.10 Frente superior de osario, Shoham North (adaptado de van den Brink, 2005: Fig. 4.9.1)

3.11 Cuello de una jarra de enterramiento, Ben Shemen (adaptado de Perrot y Ladiray, 1980: Fig. 119.7)

3.12 Frente superior de osario, Et-Taiyiba (adaptado de Yannai y Porath, 2006: Oss. 17)

3.13 Frente superior de osario, Et-Taiyiba (adaptado de Yannai y Porath, 2006: Oss. 23)

3.14 Frente superior de osario, Ben Shemen (adaptado de Perrot y Ladiray, 1980: Fig. 118.4) 


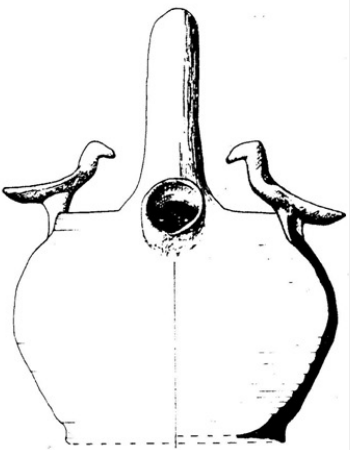

1

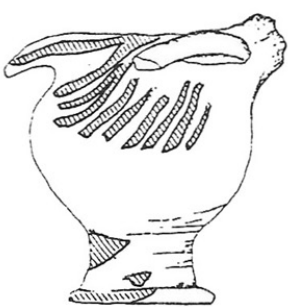

5

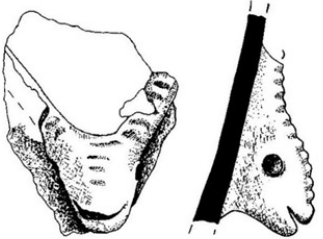

2
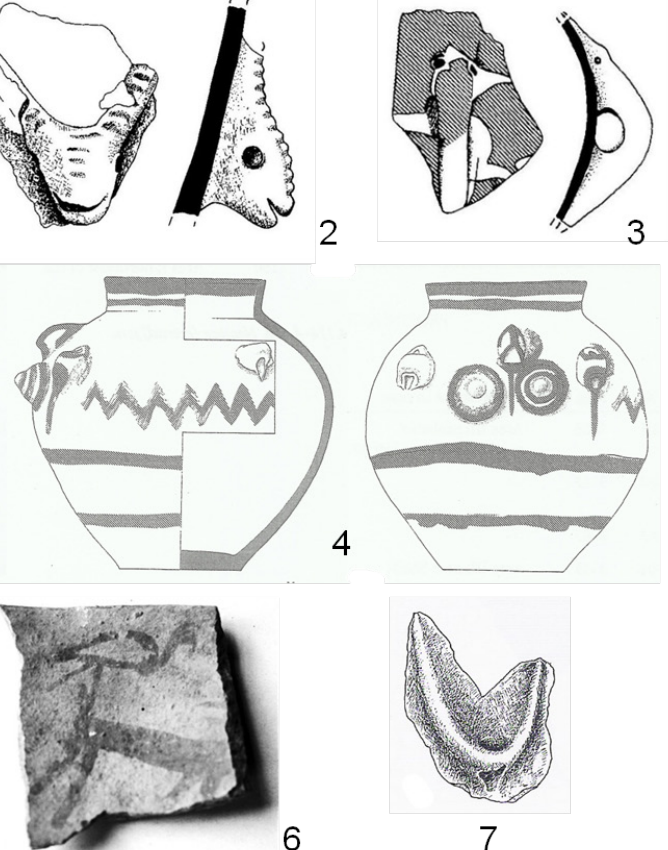

6

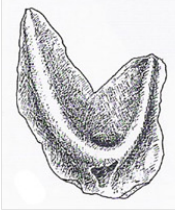

Fig. 4 Vasijas y decoraciones de vasijas

4.1 Cesto de cerámica, norte del Néguev, sitio desconocido (adaptado de Amiran, 1986: Fig. 1.B)

4.2 "Cabeza enastada aplicada" (applied horned head), Rasm Harbush (adaptado de Epstein, 1998: PI. XXIV.7)

4.3 "Asa en forma de ojos y de narices" (eye and nose handle), Khirbet el-Hutiyye (adaptado de Epstein, 1998:

PI. XXVI.14)

4.4 Vasija decorada, Peqi'in (adaptado de Shalem et al., 2013: Fig. 4.113)

4.5 Vasija en forma de ave, Palmahim (adaptado de Garfinkel, 1999: Fig. 164.2)

4.6 Tiesto pintado con un ave y un mamífero enastado, Tuleilat Ghassul (adaptado de Drabsch, 2015: Fig. 13)

4.7 “Asa en forma de cuerno" (horn handle), Rasm Harbush (adaptado de Epstein, 1998: PI. XXIII.8)
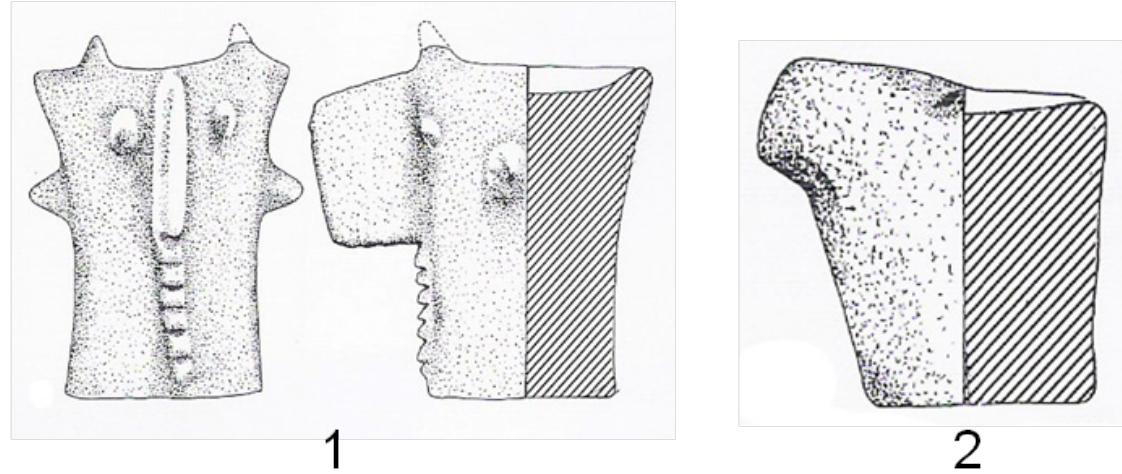

Fig. 5 Pilares de basalto

5.1 Pilar decorado, Rasm Harbush (adaptado de Epstein, 1998: PI. XXX.1)

5.2 Pilar decorado, North-west of Qalif (adaptado de Epstein, 1998: PI. XXXI.11) 

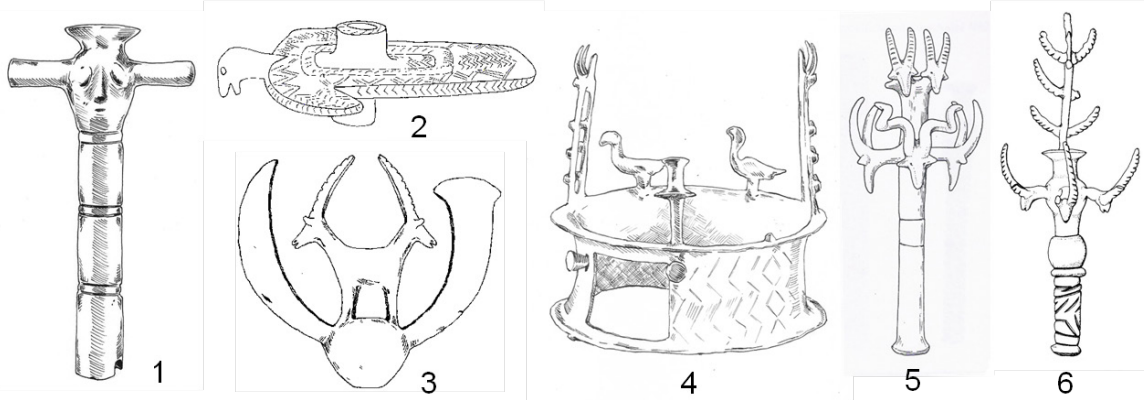

Fig. 6 Objetos de cobre

6.1 "Estandarte" o bastón decorado, Nahal Mishmar (adaptado de Bar-Adon, 1980: № 21)

6.2 "Estandarte" o bastón en forma de ave, Nahal Mishmar (adaptado de Beck, 1989: Fig. 8.C)

6.3 Maza decorada, Nahal Mishmar (adaptado de Bar-Adon, 1980: № 153 )

6.4 "Corona" o cilindro decorado, Nahal Mishmar (adaptado de Bar-Adon, 1980: № 7)

6.5 "Estandarte" o bastón decorado, Nahal Mishmar (adaptado de Moorey, 1988: Fig. 2.A)

6.6 "Estandarte" o bastón decorado, Giv’at Ha-Oranim (adaptado de Namdar et al., 2004: Fig. 5.1.17)
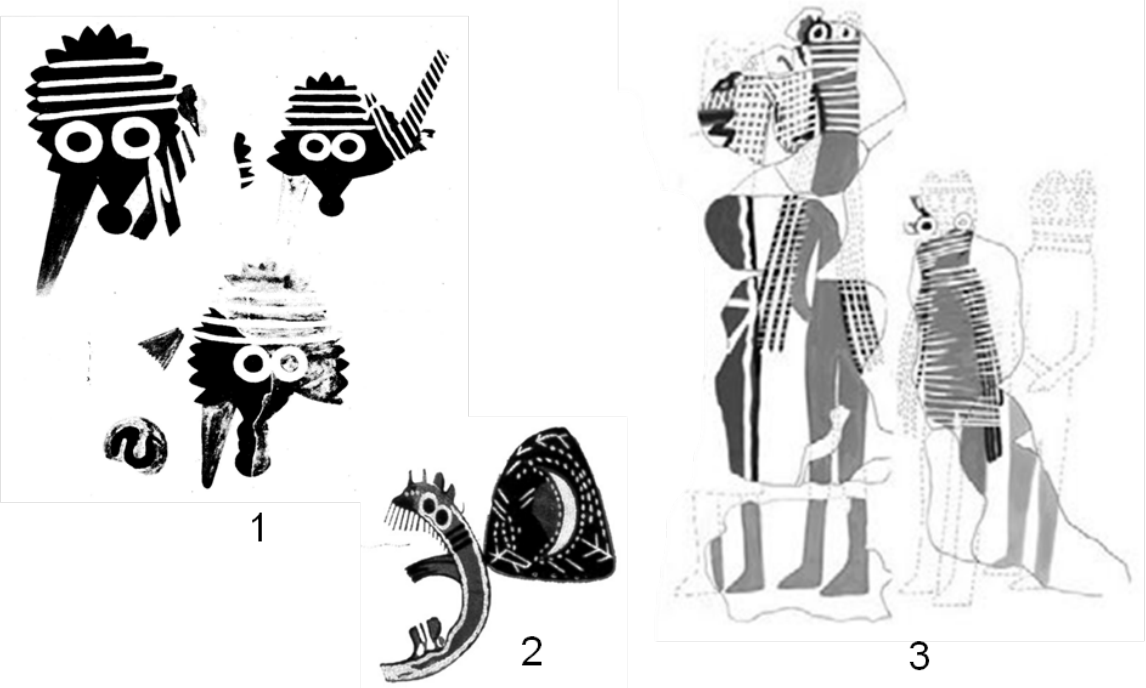

Fig. 7 Pinturas murales

7.1 Pinturas de máscaras, Tuleilat Ghassul (adaptado de Cameron, 1981: Figs. 7-8)

7.2 Pintura de animal fantástico, Tuleilat Ghassul (adaptado de Drabsch, 2015: Fig. 57)

7.3 Pintura de personajes disfrazados, Tuleilat Ghassul (adaptado de Drabsch, 2015: Fig. 146) 
